\title{
Toxicity of Radiotherapy in Patients With Collagen Vascular Disease
}

\author{
Alexander Lin, MD \\ Department of Radiation Oncology, University of Michigan, Ann Arbor \\ Eyad Abu-Isa, MD \\ Department of Radiation Oncology, University of Michigan, Ann Arbor
}

Kent A. Griffith, MPH, MS

University of Michigan Cancer Center Biostatistics Core, Ann Arbor, Michigan

Edgar Ben-Josef, MD

Department of Radiation Oncology, University of Michigan, Ann Arbor, Michigan

Follow this and additional works at: https://jdc.jefferson.edu/bodinejournal

Part of the Oncology Commons

Let us know how access to this document benefits you

\section{Recommended Citation}

Lin, MD, Alexander; Abu-Isa, MD, Eyad; Griffith, MPH, MS, Kent A.; and Ben-Josef, MD, Edgar (2008) "Toxicity of Radiotherapy in Patients With Collagen Vascular Disease," Bodine Journal: Vol. 1 : Iss. 1 , Article 2.

DOI: https://doi.org/10.29046/TBJ.001.1.001

Available at: https://jdc.jefferson.edu/bodinejournal/vol1/iss1/2

This Article is brought to you for free and open access by the Jefferson Digital Commons. The Jefferson Digital Commons is a service of Thomas Jefferson University's Center for Teaching and Learning (CTL). The Commons is a showcase for Jefferson books and journals, peer-reviewed scholarly publications, unique historical collections from the University archives, and teaching tools. The Jefferson Digital Commons allows researchers and interested readers anywhere in the world to learn about and keep up to date with Jefferson scholarship. This article has been accepted for inclusion in Bodine Journal by an authorized administrator of the Jefferson Digital Commons. For more information, please contact: JeffersonDigitalCommons@jefferson.edu. 


\section{Toxicity of Radiotherapy in Patients With Collagen Vascular Disease}

\author{
Alexander Lin, MD, ${ }^{1}$ Eyad Abu-Isa, MD, ${ }^{1}$ Kent A. Griffith, MPH, MS ${ }^{2}$ \\ Edgar Ben-Josef, MD ${ }^{1}$ \\ 'Department of Radiation Oncology, University of Michigan, Ann Arbor, Michigan. \\ ${ }^{2}$ University of Michigan Cancer Center Biostatistics Core, Ann Arbor, Michigan.
}

The following article is reprinted with permission from John Wiley \& Sons, Inc. It was originally published in CANCER, Volume 113, No. 3, pages 648-653, August 1, 2008.

\section{Background}

A diagnosis of collagen vascular disease (CVD) may predispose to radiotherapy (RT) toxicity. The objective of the current study was to identify factors that influence RT toxicity in the setting of CVD.

\section{Methods}

A total of 86 RT courses for 73 patients with CVD were delivered between 1985 and 2005. CVD subtypes include rheumatoid arthritis (RA; 33 patients), systemic lupus erythematosus (SLE; 13 patients), scleroderma ( 9 patients), dermatomyositis/polymyositis ( 5 patients), ankylosing spondylitis (4 patients), polymyalgia rheumatica/temporal arteritis (4 patients), Wegener granulomatosis (3 patients), and mixed connective tissue disorders (MCTD)/other (2 patients). Each patient with CVD was matched to 1 to 3 controls with respect to sex, race, site irradiated, RT dose ( \pm 2 Gray), and age ( \pm 5 years).

\section{Results}

There was no significant difference between CVD patients (65.1\%) and controls $(72.5 \%)$ experiencing any acute toxicity. CVD patients had a higher incidence of any late toxicity $(29.1 \% \mathrm{vs}$ $14 \% ; P=.001)$, and a trend toward an increased rate of severe late toxicity $(9.3 \%$ vs $3.7 \% ; P=.079)$. RT delivered to the breast had increased risk of severe acute toxicity, whereas RT to the pelvis had increased risk of severe acute and late toxicity. RT administered in the setting of scleroderma carried a higher risk of severe late toxicity, whereas RT to SLE patients carried a higher risk of severe acute and late toxicity.

\section{Conclusions}

Although generally well tolerated, RT in the setting of CVD appears to carry a higher risk of late toxicity. RT to the pelvis or in the setting of SLE or scleroderma may predispose to an even greater risk of severe toxicity. These issues should be considered when deciding whether to offer RT for these patients. Cancer 2008;113:648-53. @2008 American Cancer Society.

\section{Key Words: radiotherapy, collagen diseases, complications, adverse effects.}

The decision of whether to offer therapeutic radiotherapy (RT) to patients with collagen vascular disease (CVD) continues to be a challenging one. It is believed that CVD may predispose patients to increased toxicity, and many practicing oncologists believe that a diagnosis of CVD is a relative contraindication to RT. However, to our knowledge, the available literature on this issue has been mixed. Early publications were largely case reports of CVD patients with increased toxicity from RT. ${ }^{1-8}$ However, 2 separate matched control studies failed to observe any increased risk of acute or late complications in patients with CVD versus patients without CVD. ${ }^{9,10}$ Other publications suggested that patients with nonrheumatoid arthritis CVD, ${ }^{11,12}$ or patients with specific subtypes of CVD, may be at increased toxicity risk. ${ }^{13-15}$ Further complicating the issue is the finding that some commonly prescribed medications, many of which are used in patients with CVD, may alter the radiation toxicity profile. ${ }^{16-18}$ The goals of this matched control study were to determine whether patients with CVD were at a higher risk of RT-associated toxicity compared with patients without CVD and to identify factors that influence radiation toxicity in the setting of CVD, with particular emphasis on medications (antirheumatic drugs, nonsteroidal antiinflammatory drugs [NSAIDs], statins, and calcium channel blockers [CCBs]) that when taken concurrently may alter radiation toxicity.

\section{Materials and Methods}

After Institutional Review Board approval, 101 patients with a diagnosis of CVD treated in the Department of Radiation Oncology at the University of Michigan between 1985 and 2005 were identified. A total of 116 unique RT courses were delivered to these patients. A majority of these courses were delivered with 3-dimensional (3D) conformal techniques. Twenty-two cases were excluded because the diagnosis of CVD was made after the completion of RT. Of the remaining 94 RT courses, 8 courses could not be matched with a control. This left an analyzable sample of 86 CVD RT courses for 73 unique patients. Thirty-three patients had rheumatoid arthritis (RA), 13 had systemic lupus erythematosus (SLE), 9 had scleroderma, 5 had dermatomyositis/polymyositis, 4 had ankylosing spondylitis, 4 had polymyalgia rheumatica/temporal arteritis, 3 had Wegener granulomatosis, and 2 had mixed connective tissue disorders (MCTD)/ other. Neither polymyalgia rheumatica/temporal arteritis nor Wegener granulomatosis are defined as a CVD; however, their inclusion was based on the systemic vasculitis noted with these diseases and its potential impact on RT toxicity. The mean age of the patients at time of RT was 58.2 years (range, 23-84 years) and the majority of patients were women $(73.3 \%)$. Sixty patients received only a single RT course, with 13 patients receiving 2 RT courses in this dataset. Their medical records were reviewed for the following characteristics: age, sex, race, CVD type and activity, date of CVD diagnosis, concurrent medications, cancer diagnosis, chemotherapy treatment details, site and dose schedule of RT, acute and late toxicity, pattern of failure, and survival.

Of the total 86 RT courses, 15 were delivered to the thorax, 14 to the skin, 12 to the head and neck, 11 to bone, 11 to the pelvis, 8 to the breast, 6 to total body, 4 to the central nervous system, 4 to the abdomen, and 1 to an extremity.

Each CVD patient was then matched with a control patient without CVD for sex, race, site of disease treated by RT, dose delivered ( \pm 2 Gray [Gy]), and age at time of RT delivery ( \pm 5 years). For CVD patients with many matching controls, the controls with thesmallest difference with regard to RT dose and age at 
RT were chosen, with importance placed on minimizing the difference in RT dose over the difference in age at RT. An attempt was made to find 3 matching controls for each CVD RT course. Fifty-nine courses were matched to 3 controls, 18 courses were matched to 2 controls, and 9 courses were matched to a single control.

Acute toxicity was defined as toxicity from the time of commencement of RT through Day 90 after treatment and was scored using the Radiation Therapy Oncology Group (RTOG) common toxicity criteria. ${ }^{19}$ Late toxicity was defined as occurring after Day 90 posttreatment, and was scored according to the RTOG/European Organization for Research and Treatment of Cancer (EORTC) late radiation morbidity scoring schema. ${ }^{20}$ Severe acute or late toxicity was defined as $\geq$ grade 3 .

Because this is a match-pairs, case-control analysis, conditional logistic regression techniques were used. Because sex, age at RT, anatomic site treated, and RT dose were matched for by the design, these covariates were not adjusted for in the modeling process because their impact has been adjusted for by the study design. The remaining covariates of interest were as follows: concurrent infusional chemotherapy administration, and the use of steroids, NSAIDS, statins, CCBs, antimalarial antirheumatic drugs, and oral cytotoxic antirheumatics. Many of the medications apply only to the CVD cases and could not be adjusted for in the overall model. The medication list is therefore most appropriately used to help predict toxicity in the CVD group separately.

Overall crude rates for toxicity are reported by the anatomic site of RT delivery and by CVD subtype of the cases. Although these rates are instructive, formal comparison at the matched case-control level has not been attempted because of the small sample size. Formal comparisons were limited to the entire population. $P$ values $\leq .05$ are considered statistically significant.

There were 4 endpoints of interest: any acute toxicity, severe acute toxicity, any late toxicity, and severe late toxicity.

\section{Results}

\section{Acute Toxicity}

With a median follow-up time of 1.3 years for each group, overall, there was no significant difference noted with regard to the incidence of acute toxicity between CVD and control cases, with $65.1 \%$ of CVD patients experiencing any acute toxicity, compared with $72.5 \%$ of control patients (Table 1). The incidence of severe acute toxicity was similar in both groups (10.5\% vs $10.4 \%)$.

Table 1. Acute and Late Toxicity by CVD Status

\begin{tabular}{|c|c|c|c|c|c|c|c|c|}
\hline \multirow[b]{2}{*}{$\begin{array}{l}\text { Frequency } \\
\text { (percent) }\end{array}$} & \multicolumn{6}{|c|}{ Toxicity Grade } & \multirow{2}{*}{$\begin{array}{c}\text { Any } \\
P^{\dagger}\end{array}$} & \multirow{2}{*}{$\frac{\text { Severe }}{P^{\dagger}}$} \\
\hline & 0 & 1 & 2 & 3 & 4 & 5 & & \\
\hline \multicolumn{9}{|l|}{ Acute Toxicity ${ }^{*}$} \\
\hline CVD cases & $30(34.9)$ & $19(22.1)$ & $28(32.6)$ & $9(10.5)$ & 0 & 0 & - & - \\
\hline Control Cases & $61(27.5)$ & $63(28.4)$ & $75(33.8)$ & $23(10.4)$ & 0 & 0 & .97 & .075 \\
\hline \multicolumn{9}{|l|}{ Late Toxicity } \\
\hline CVD cases & $61(70.9)$ & $10(11.6)$ & $7(8.1)$ & $4(4.7)$ & $2(2.3)$ & $2(2.3)$ & - & - \\
\hline Control Cases & $191(86.0)$ & $14(6.3)$ & $9(4.1)$ & $7(3.2)$ & $1(0.5)$ & 0 & .0010 & .079 \\
\hline \multicolumn{9}{|c|}{$\begin{array}{l}\text { CVD indicates collagen vascular disease. } \\
{ }^{*} \text { Acute toxicity was defined as toxicity from the commencement of radiotherapy through Day } 90 \text { after treatment, and } \\
\text { was scored using the Radiation Therapy Oncology Group (RTOG) common toxicity criteria. }{ }^{19}\end{array}$} \\
\hline \multicolumn{9}{|c|}{${ }^{\dagger}$ Exact $\mathrm{P}$ value was derived from conditional logistic regression analysis. } \\
\hline \multicolumn{9}{|c|}{$\begin{array}{l}{ }^{\ddagger} \text { Late toxicity was defined as that occurring after Day } 90 \text { after treatment, and was scored according to } \\
\text { the RTOG/European Organization for Research and Treatment of Cancer (EORTC) late radiation morbidity } \\
\text { scoring schema. }{ }^{20}\end{array}$} \\
\hline
\end{tabular}

\section{Late Toxicity}

Overall, patients with a CVD diagnosis had a significantly higher incidence of any late toxicity ( $29.1 \%$ vs $14 \% ; P=.001)$, with a trend toward increased severe late toxicity $(9.3 \%$ vs $3.7 \% ; P=.079)$ (Table 1$)$.

\section{Table 2. Acute and Late Toxicity by Anatomic Site of} Radiotherapy Delivery

\begin{tabular}{|c|c|c|c|c|c|c|}
\hline \multirow{2}{*}{$\begin{array}{l}\text { Frequency } \\
\text { (Percent) }\end{array}$} & \multicolumn{6}{|c|}{ Acute toxicity grade ${ }^{*}$} \\
\hline & 0 & 1 & 2 & 3 & 4 & 5 \\
\hline \multicolumn{7}{|l|}{ Bone } \\
\hline Cases $(\mathrm{n}=11)$ & $11(100.0)$ & 0 & 0 & 0 & 0 & 0 \\
\hline Controls $(\mathrm{n}=28)$ & $20(71.4)$ & $4(14.3)$ & $4(14.3)$ & 0 & 0 & 0 \\
\hline \multicolumn{7}{|l|}{ Breast } \\
\hline Cases $(\mathrm{n}=8)$ & $1(12.5)$ & $1(12.5)$ & $4(50.0)$ & $2(25.0)$ & 0 & 0 \\
\hline Controls $(n=20)$ & 0 & $6(30.0)$ & $14(70.0)$ & 0 & 0 & 0 \\
\hline \multicolumn{7}{|l|}{ Head and neck } \\
\hline Cases $(\mathrm{n}=12)$ & 0 & $4(33.3)$ & $6(50.0)$ & $2(16.7)$ & 0 & 0 \\
\hline Controls $(\mathrm{n}=32)$ & $5(15.6)$ & $8(25.0)$ & $12(37.5)$ & $7(21.9)$ & 0 & 0 \\
\hline \multicolumn{7}{|l|}{ Pelvis } \\
\hline Cases $(\mathrm{n}=11)$ & 0 & $1(9.1)$ & $6(54.6)$ & $4(36.4)$ & 0 & 0 \\
\hline Controls $(\mathrm{n}=28)$ & $2(7.1)$ & $7(25.0)$ & $16(57.1)$ & $3(10.7)$ & 0 & 0 \\
\hline \multicolumn{7}{|l|}{ Skin } \\
\hline Cases $(\mathrm{n}=14)$ & 0 & $10(71.4)$ & $4(28.6)$ & 0 & 0 & 0 \\
\hline Controls $(\mathrm{n}=35)$ & $1(2.9)$ & $17(48.6)$ & $14(40.0)$ & $3(8.6)$ & 0 & 0 \\
\hline \multicolumn{7}{|l|}{ Thorax } \\
\hline Cases $(\mathrm{n}=15)$ & $6(40.0)$ & $3(20.0)$ & $6(40.0)$ & 0 & 0 & 0 \\
\hline Controls $(\mathrm{n}=41)$ & $14(34.2)$ & $12(29.3)$ & $8(19.5)$ & $7(17.1)$ & 0 & 0 \\
\hline \multicolumn{7}{|l|}{ Other Sites $^{\dagger}$} \\
\hline Cases $(\mathrm{n}=15)$ & $12(80.0)$ & 0 & $3(20.0)$ & 0 & 0 & 0 \\
\hline Controls $(\mathrm{n}=38)$ & $19(50.0)$ & $9(23.7)$ & $6(15.8)$ & $4(10.5)$ & 0 & 0 \\
\hline
\end{tabular}

Late toxicity grade f $^{\ddagger}$

\begin{tabular}{|c|c|c|c|c|c|c|}
\hline & $\mathbf{0}$ & 1 & 2 & 3 & 4 & 5 \\
\hline \multicolumn{7}{|l|}{ Bone } \\
\hline Cases $(\mathrm{n}=11)$ & $11(100.0)$ & 0 & 0 & 0 & 0 & 0 \\
\hline Controls $(\mathrm{n}=28)$ & $27(96.4)$ & $1(3.6)$ & 0 & 0 & 0 & 0 \\
\hline \multicolumn{7}{|l|}{ Breast } \\
\hline Cases $(\mathrm{n}=8)$ & $5(62.5)$ & $1(12.5)$ & $2(25.0)$ & 0 & 0 & 0 \\
\hline Controls $(\mathrm{n}=20)$ & $13(65.0)$ & $4(20.0)$ & $3(15.0)$ & 0 & 0 & 0 \\
\hline \multicolumn{7}{|l|}{ Head and neck } \\
\hline Cases $(\mathrm{n}=12)$ & $6(50.0)$ & $2(16.7)$ & $2(16.7)$ & $2(16.7)$ & 0 & 0 \\
\hline Controls $(\mathrm{n}=32)$ & $24(75.0)$ & $2(6.3)$ & $2(6.3)$ & $3(9.4)$ & $1(3.1)$ & 0 \\
\hline \multicolumn{7}{|l|}{ Pelvis } \\
\hline $\begin{array}{l}\text { Cases }(\mathrm{n}=11) \\
(9.1)\end{array}$ & $4(36.4)$ & $2(18.2)$ & $1(9.1)$ & $1(9.1)$ & $2(18.2)$ & 1 \\
\hline Controls $(\mathrm{n}=28)$ & $21(75.0)$ & $2(7.1)$ & $3(10.7)$ & $2(7.1)$ & 0 & 0 \\
\hline \multicolumn{7}{|l|}{ Skin } \\
\hline Cases $(\mathrm{n}=14)$ & $10(71.4)$ & $4(28.6)$ & 0 & 0 & 0 & 0 \\
\hline Controls $(\mathrm{n}=35)$ & $35(100.0)$ & 0 & 0 & 0 & 0 & 0 \\
\hline \multicolumn{7}{|l|}{ Thorax } \\
\hline Cases $(\mathrm{n}=15)$ & $11(73.3)$ & $1(6.7)$ & $2(13.3)$ & $1(6.7)$ & 0 & 0 \\
\hline Controls $(\mathrm{n}=41)$ & $36(87.8)$ & $4(9.8)$ & $1(2.4)$ & 0 & 0 & 0 \\
\hline \multicolumn{7}{|l|}{ Other Sites $^{\dagger}$} \\
\hline $\begin{array}{l}\text { Cases }(\mathrm{n}=15) \\
(6.7)\end{array}$ & $14(93.3)$ & 0 & 0 & 0 & 0 & 1 \\
\hline Controls $(\mathrm{n}=38)$ & $36(94.7)$ & 0 & 0 & $2(5.3)$ & 0 & 0 \\
\hline
\end{tabular}

CVD indicates collagen vascular disease.

* Acute toxicity was defined as toxicity from the commencement of radiotherapy through Day 90 after treatment, and was scored using the Radiation Therapy Oncology Group (RTOG) common toxicity criteria. ${ }^{19}$

${ }^{\dagger}$ Other sites included the abdomen, central nervous system, extremities, and total body.

${ }^{\ddagger}$ Late toxicity was defined as that occurring after Day 90 after treatment, and was scored according to the RTOG/European Organization for Research and Treatment of Cancer (EORTC) late radiation morbidity scoring schema. ${ }^{20}$ 
Table 3. Distribution of Toxicity (Percent) by CVD Case/Control Status, by CVD Subtype

\begin{tabular}{|c|c|c|c|c|c|c|c|c|}
\hline \multirow[b]{3}{*}{ CVD Subtype } & \multicolumn{4}{|c|}{ Acute $^{\star}$} & \multicolumn{4}{|c|}{ Late $^{\dagger}$} \\
\hline & \multicolumn{2}{|c|}{ Any } & \multicolumn{2}{|c|}{ Severe } & \multicolumn{2}{|c|}{ Any } & \multicolumn{2}{|c|}{ Severe } \\
\hline & CVD & Control & CVD & Control & CVD & Control & CVD & Control \\
\hline Rheumatoid arthritis & 64.9 & 76.2 & 10.8 & 9.9 & 29.7 & 13.9 & 2.7 & 4.0 \\
\hline Systemic lupus erythematosus & 88.2 & 76.2 & 29.4 & 11.9 & 41.2 & 19.1 & 35.3 & 4.8 \\
\hline Dermatomyositis/polymyositis & 66.7 & 91.7 & 0 & 8.3 & 16.7 & 8.3 & 0 & 0 \\
\hline Ankylosing spondylitis & 0 & 0 & 0 & 0 & 0 & 0 & 0 & 0 \\
\hline Wegener granulomatosis & 100 & 100 & 0 & 16.7 & 33.3 & 33.3 & 0 & 0 \\
\hline Scleroderma & 30.0 & 53.9 & 0 & 11.5 & 20.0 & 15.4 & 10.0 & 3.9 \\
\hline Polymyalgia rheumatica/temporal arteritis & 85.7 & 80.0 & 0 & 10.0 & 28.6 & 5.0 & 0 & 5.0 \\
\hline Mixed connective tissue disorder/other & 50.0 & 83.3 & 0 & 16.7 & 50.0 & 16.7 & 0 & 0 \\
\hline
\end{tabular}

CVD indicates collagen vascular disease.

${ }^{*}$ Acute toxicity was defined as toxicity from the commencement of radiotherapy through Day 90 after treatment, and was scored using the Radiation Therapy Oncology Group (RTOG) common toxicity criteria. ${ }^{19}$

${ }^{\dagger}$ Late toxicity was defined as that occurring after Day 90 after treatment, and was scored according to the RTOG/European Organization for Research and Treatment of Cancer (EORTC) late radiation morbidity scoring schema. ${ }^{20}$

\section{Toxicity by Irradiated Site}

Although overall there was no significant difference noted with regard to the incidence of acute toxicity, CVD patients treated with RT to some anatomic sites were found to have a higher rate of severe acute toxicity (Table 2). RT to CVD patients produced higher crude rates of grade 3 acute toxicity when delivered to the breast (2 patients [25\%] vs 0 patients [0\%]) or pelvis (4 patients [36\%] vs 3 patients [11\%]). For the 2 CVD patients with severe breast acute toxicity, toxicity consisted of grade 3 skin desquamation. For the 4 CVD patients with severe pelvic acute toxicity, 3 had grade 3 skin desquamation alone, whereas the fourth patient had grade 3 skin desquamation, cystitis, and diarrhea/dehydration. However, given the small sample sizes per group and the matched case-control design of the study, formal statistical comparisons were not attempted.

RT to several anatomic sites produced a higher crude rate of any late toxicity in CVD patients (Table 2), including the head and neck (6 patients [50\%] vs 8 patients [25\%]), pelvis (7 patients [64\%] vs 7 patients [25\%]), skin (4 patients [29\%] vs 0 patients [0\%]), and thorax (4 patients [27\%] vs 5 patients [12\%]). The incidence of severe toxicity was greater mainly only in the pelvis subgroup, with 4 CVD patients (36\%) experiencing grade $3+$ toxicity (consisting of small bowel ulceration and dysuria), including 1 grade 5 event (intestinal perforation), versus 2 in the control group with severe toxicity (7\%). RT to the other anatomic sites was found to be equally well tolerated by both CVD and control patients.

\section{Toxicity by CVD Subtype}

Table 3 summarizes the toxicity information when separated by CVD subtype. The only patients who had an appreciably higher crude incidence of any acute toxicity when compared with controls were patients with SLE ( $88.2 \%$ vs $76.2 \%)$. Patients with SLE were also the only CVD subset found to have a higher crude risk of severe acute toxicity (29.4\% vs $11.9 \%)$, which was the highest rate of severe acute toxicity noted among all CVD subtypes. Otherwise, severe acute toxicity was uncommon.

Compared with controls, the incidence of any late toxicity was observed to be higher in several CVD subtypes: RA ( $29.7 \%$ vs $13.9 \%)$, SLE $(41.2 \%$ vs $19.1 \%)$, dermatomyositis/polymyositis ( $16.7 \%$ vs $8.3 \%)$, polymyalgia rheumatica/temporal arteritis (28.6\% vs 5.0\%), and MCTD/other $(50.0 \%$ vs $16.7 \%)$. The incidence of severe late toxicity was generally low among both CVD and control patients; however, patients with SLE (35.3\% vs $4.8 \%)$ and scleroderma ( $10.0 \%$ vs $3.9 \%)$ had a higher risk of severe late toxicity versus controls.

Table 4. Medications and Frequency of Use for CVD Patients

\begin{tabular}{lcc}
\hline & \multicolumn{2}{c}{ Cases $(\boldsymbol{n}=\mathbf{8 6})$} \\
\cline { 2 - 3 } Medication & Frequency & Percentage \\
\hline NSAIDs & 34 & 39.5 \\
\hline Corticosteroids & 32 & 37.2 \\
\hline Antimalarials & 25 & 29.1 \\
\hline CCB & 20 & 23.2 \\
\hline Chemotherapy & \\
\hline Oral cytotoxic, antirheumatic drugs & 18 & 20.9 \\
\hline Statins & 17 & 19.8 \\
\hline
\end{tabular}

CVD indicates collagen vascular disease; NSAIDs, nonsteroidal antiinflammatory drugs; $\mathrm{CCB}$, calciumchannel blocker.

${ }^{*}$ Concurrent with radiotherapy.

\section{Concomitant Medication Use by CVD Patients}

Table 4 lists several types of medications and their frequencies of use by CVD patients. Tables 5 and 6 list the distribution of acute and late toxicities for CVD cases, respectively. None of the following medications was found to be significantly associated with a risk of any acute or late toxicity: corticosteroids, NSAIDs, statins, CCBs, and antimalarials. The use of oral cytotoxic, rheumatologic agents was found to be significantly associated with a decreased risk of any acute toxicity $(P=.0263)$, and concurrent infusional chemotherapy was found to be significantly associated with an increased risk of severe acute toxicity $(P=.0022)$. Chemotherapy was the only concomitant medication that was found to be associated with increased risk of any $(P=.009)$ or severe $(P=.009)$ late toxicity.

\section{Discussion}

Delivering RT to patients with CVD continues to be a challenging clinical dilemma for radiation oncologists. The existing literature is difficult to interpret because of the heterogeneity in CVD subtype and activity, the variations in RT dose and site of treatment, as well as the potential role of concomitant medications in altering toxicity. Morris and Powell ${ }^{11}$ reported that severe late effects were associated with CVD other than 


\section{References}

1. Fleck R, McNeese MD, Ellerbroek NA, et al. Consequences of breast irradiation in patients with pre-existing collagen vascular disease. Int J Radiat Oncol Biol Phys. 1989;17:829-833.

2. Olivotto IA, Fairey RN, Gillies JH, et al. Fatal outcome of pelvic radiotherapy for carcinoma of the cervix in a patient with systemic lupus erythematosus. Clin Oncol. 1989;40: 83-84.

3. Ransom DT, Cameron FG. Scleroderma: a possible contraindication to lumpectomy and radiotherapy in breast carcinoma. Australas Radiol. 1987;31:317-318.

4. Robertson JM, Clarke DH, Pevzner MM, et al. Breast conservation therapy: severe breast fibrosis after radiation therapy in patients with collagen vascular disease. Cancer. 1991;68:502-508.

5. Teo P, Tai TH, Choy D. Nasopharyngeal carcinoma with dermatomyositis. Int J Radiat Oncol Biol Phys. 1989;16:471-474.

6. Varga J, Haustein UF, Creech RH, et al. Exaggerated radiationinduced fibrosis in patients with systemic sclerosis. JAMA. 1991;265:3292-3295.

7. Abu-Shakra M, Lee P. Exaggerated fibrosis in patients with systemic sclerosis (scleroderma) following radiation therapy. J Rheumatol. 1993;20:1601-1603.

8. Hareyama M, Nagakura $H$, Tamakawa $M$, et al. Severe reaction after chemoradiotherapy of nasopharyngeal carcinoma with collagen disease. Int J Radiat Oncol Biol Phys. 1995; 33:971.

9. Ross JG, Hussey DH, Mayr NA, et al. Acute and late reactions to radiation therapy in patients with collagen vascular diseases. Cancer. 1993;71:3744-3752.

10. Phan C, Mindrum M, Silverman C, et al. Matched-control retrospective study of the acute and late complications in patients with collagen vascular diseases treated with radiation therapy. Cancer J. 2003;9:461-466.

11. Morris MM, Powell SN. Irradiation in the setting of collagen vascular disease: acute and late complications. J Clin Oncol. 1997;15:2728-2735.

12. Chon BH, Loeffler JS. The effect of nonmalignant systemic disease on tolerance to radiation therapy. Oncologist. 2002;7:136-143.

13. Chen AM, Obedian E, Haffty BG. Breast-conserving therapy in the setting of collagen vascular disease. Cancer J. 2001;7:480-491.

14. Gold DG, Miller RC, Petersen IA, et al. Radiotherapy for malignancy in patients with scleroderma: the Mayo clinic experience. Int J Radiat Oncol Biol Phys. 2007;67:559-567.

15. Pinn ME, Gold DG, Petersen IA, et al. Systemic lupus erythematosus, radiotherapy, and the risk of acute and chronic toxicity: the Mayo Clinic experience. Int J Radiat Oncol Biol Phys. 2007 Dec 28 [Epub ahead of print].

16. Irwin B, Ben-Josef E, Tobi M. Calcium channel blockers may radiosensitize, statins and NSAIDs may radioprotect patients from radiation proctitis: a case control study. Presented at the American Gastroenterology Associations' Digestive Disease Week, Los Angeles, California, May 20-25, 2006.

17. Fuks Z, Smith KC. Effect of quinacrine on $\mathrm{x}$-ray sensitivity and the repair of damaged DNA in Escherichia coli K-12. Radiat Res. 1971;48:63-73.

18. Voiculetz N, Smith KC, Kaplan HS. Effect of quinacrine on survival and DNA repair in $\mathrm{x}$-irradiated Chinese hamster cells. Cancer Res. 1974;34:1038-1044.

19. Trotti A, Byhardt R, Stetz J, et al. Common toxicity criteria: version 2.0 an improved reference for grading the acute effects of cancer treatment: impact on radiotherapy. Int J Radiat Oncol Biol Phys. 2000;47:13-47.

20. LENT SOMA scales for all anatomic sites. Int $J$ Radiat Oncol Biol Phys. 1995;31:1049-1091 